\title{
Japanese University Students' Perceptions of Foreign English Teachers
}

\author{
Soyhan Egitim ${ }^{1} \&$ Travis Garcia ${ }^{2}$ \\ ${ }^{1}$ Faculty of Human Life Design, Toyo University, Saitama, Japan \\ ${ }^{2}$ Faculty of Engineering, Tokyo Denki University, Tokyo, Japan \\ Correspondence: Soyhan Egitim, Faculty of Human Life Design, Toyo University, Saitama, Japan.
}

Received: March 17, 2021

Accepted: March 31, 2021

Online Published: April 12, 2021

doi: $10.5539 /$ elt.v14n5p13

URL: https://doi.org/10.5539/elt.v14n5p13

\begin{abstract}
This study aims to understand Japanese university students' perceptions of foreign English teachers (FETs) through a two-phased exploratory sequential mixed-methods design. During the initial phase, a quantitative survey was performed with first and second-year Japanese university students $(n=377)$. Despite a lack of precision and a high dispersion measure, the Quantitative data analysis revealed certain outliers. A significant number of participants viewed their FETs as more of an entertainer, preferred FETs of American/European heritage, and believed FETs of Asian descent may not be able to teach the language and culture as effectively as FETs of American/European heritage. Thus, a qualitative inquiry was performed to explain and build upon the quantitative findings. Two focus groups with students from the quantitative survey were given interviews. The responses confirmed the existence of phenotypical, gender, and personality FET stereotypes in Japanese university EFL classes. In addition, past educational experiences, socio-cultural factors, and mass media were also found influential in students' perceptions of FETs. Based on the findings from the focus group interviews, the researchers propose intercultural activities as an effective pedagogical strategy to promote reflective teaching practices and intercultural competence in Japanese university EFL classes.
\end{abstract}

Keywords: foreign English teacher, intercultural awareness, Japanese students, perceptions, reflective, stereotypes

\section{Introduction}

Previous research studies suggest that there may be certain preconceived notions about ideal FETs in Japanese society (Appleby, 2014; Bailey, 2007; Houghton, 2014; Kubota, 2011; Nagatomo, 2016). The general assumption is FETs should be male, Caucasian with an entertaining persona. The implications of these FET stereotypes on Japanese English education are well-documented in various studies (Appleby, 2014; Bailey, 2007; Houghton, 2014; Kubota, 2011; Nagatomo, 2016). However, there has been little research on how Japanese university students perceive FETs from different ethnic and cultural backgrounds in the presence of the aforementioned stereotypes.

Thanks to rapid globalization, the changing landscape of Japanese tertiary English education has created new opportunities for students to interact with FETs from different ethnic and cultural backgrounds. Thus, teachers who fall outside of the aforementioned FET stereotypes face challenges during their interactions with students. Therefore, this study attempts to explore stereotypes through the research questions of "What are Japanese university students' perceptions of FETs?" and "What are the potential implications of students' perceptions of FETs?" By addressing these research questions, the study aims to offer valuable insights into students' perspectives of FETs and the challenges stemming from those perspectives. In the end, the study proposes intercultural awareness building as an effective pedagogical strategy to help students develop a tolerant and accepting view of people from different ethnic and cultural backgrounds.

\section{English Language Education in Japan}

In recent years, psychological and relational aspects of language acquisition have become a focal point of second language literature. More emphasis has been placed on concepts, such as learner development, autonomy, and self-directed learning (Benson, 2013; Dornyei, 2009; King, 2013). This new direction in language teaching and learning has also manifested itself in Japan with key educational reforms to enhance college English education (MEXT, 2014a). The main objective was to promote a student-oriented educational environment with a focus on fostering global Japanese citizens. Therefore, many universities expanded their international recruitment (MEXT, 
2014a) and involved their existing full-time international faculty in departmental and policy decision-making.

The influence of this internationalization was also reflected in college English education premised on learner-centered instruction, in which the teacher takes on a facilitative role to help students develop their autonomous learning skills (Benson, 2013; Dornyei, 2013). Thus, teachers focus on content-based language education by engaging students in the discussion and presentation of various intercultural contents. However, due to years of exposure to teacher-controlled instruction with a focus on entrance examinations, many students are unaccustomed to this style and experience difficulties with their adaptation into a learner-centered educational environment (Edwards, 2014; Hosoki, 2011; Kawashima, 2009; King, 2013, Loucky \& Ware, 2016).

English classes are mainly taught by Japanese teachers of English (JTEs) who are assisted by FETs, commonly referred to as "Assistant language teachers" (ALTs) until students go to university. A study conducted by Kizuka (2007) suggested that JTEs' responsibility is to assure that students have a good grasp of grammar and vocabulary, while ALTs focus on engaging students in speaking activities through games, songs, and other communication activities (Esaki \& Shintani, 2010). Most Japanese students in the public school system are exposed to this co-teaching model until they enter university. As a result, some students may hold certain preconceived notions regarding JTEs and FETs before entering college (Johannes, 2012). These preconceived notions may result in EFL teacher stereotypes and affect teacher-student dynamics.

\section{English Teacher Stereotypes in Japanese Educational Settings}

The potential implications of the stereotypical notions ascribed to FETs are well-documented in academic settings. A study performed by Shimizu (2000) revealed that some university students considered FETs more animated and exciting than their JTEs while viewing their JTEs more knowledgeable and scholarly. Walkinshaw and Oanh (2014) argued that shared cultural values and communication styles allow building trust and rapport between the teacher and students while, different cultural values and communication styles may lead to misunderstandings and miscommunications.

Yazawa's (2017) study also revealed that two-thirds of the students preferred to study English with their JTEs rather than FETs due to the ease of using their L1 (arterial language) and shared cultural beliefs and values with their JTEs. The rest of the respondents preferred FETs due to their interest in the English language, teachers' language authenticity, clear pronunciation, and the students' self-realization of the English language acquisition process.

On the other hand, more recent literature indicated that FET stereotypes in Japanese society create a perception of English classes as a leisure pursuit rather than an opportunity to develop language skills (Appleby, 2014; Bailey, 2007; Kubota, 2011; Hooper \& Snyder, 2017; Nagatomo, 2016). These preconceived notions were also depicted in a popular manga named "Charisma Man" portraying FETs as unqualified Caucasian men whose main job is to entertain students in English classes (Hooper \& Sneijder, 2017).

Appleby (2013) reflected on Caucasian teachers' perspective of FET stereotypes and argued that due to such stereotypes, Caucasian FETs struggle to establish a professional identity independent from appearance and personality. Furthermore, teachers falling outside of the FET stereotypes, including female FETs and FETs of non-American/non-European descent, may experience challenges during their job pursuits as they don't fit the ideal FET image (Appleby, 2014; Bailey, 2007; Houghton et al., 2014).

The notion of male privilege was also highlighted by a number of scholars in the EFL field (Appleby, 2014; Kobayashi, 2014; Kubota, 2011; Nagatomo, 2016). According to Nagatomo (2015), female FETs are under societal pressure to fulfill stereotypical roles such as wives and mothers. While men enjoy respect and stability brought by marriage, women's ability to dedicate themselves to a career is often questioned due to their marital status or the possibility of a future marriage. Therefore, many female FETs either have difficulty pursuing a successful full-time career or prefer to work part-time. These gender stereotypes are also apparent in EFL recruitment practices. According to Nagatomo (2016), male FETs are three times more likely to be employed than female FETs. In other words, students are three times more likely to study English with a male FET during their university education. Therefore, more exposure to male teachers, in general, could further reinforce gender stereotypes.

\subsection{The Mass Media's Role in Reinforcing Stereotypes}

Previous studies suggest that the mass media's influence in reinforcing gender and ethnic stereotypes extends beyond Charisma Man. According to Merskin (2011), mass media plays a major role in manipulating people's desires, beliefs, and attitudes to "construct, reinforce, perpetuate, and maintain stereotypes" (p. 4). Buckley (2009) shed further light on the Japanese media's influence on ethnic and gender stereotypes with his illustration of 
foreigners being portrayed as blond Caucasian men and women performing certain gaijin (the Japanese word for foreigner) stereotypes in Japanese TV shows. In one particular TV show, a Caucasian man was portrayed as an arrogant character, squaring his shoulders, speaking loudly, and telling jokes in English accented Japanese (as cited in Fukuda, 2017). According to Fukuda (2017), this type of illustration is prevalent in the media and only serves the purpose of reinforcing white male stereotypes in Japan.

Inaccurate cultural representations of minorities are not limited to Caucasian people in Japan. According to Brewer (2011), the media may use "non-recognition, ridicule, and regulation" strategies to reinforce different ethnic stereotypes. Frequent appearances of blackface performers in Japanese TV shows and lack of media coverage of different ethnic groups from Asian countries can be perceived as ridicule and non-recognition media strategies (Sani, 2013; Yoshimoto et al., 2010). As a result, the media promotes the social identity and self-esteem of the majority against the minority groups (Brewer, 2011; Fukuda, 2017; Houghton et al., 2014; Kubota, 2011; Kubota \& Fujimoto, 2013). In this regard, it is essential to delve deeper into certain socio-cultural factors, such as cultural identity and collectivism within the Japanese context, to understand the mass media's motivation.

\subsection{Japanese Collectivist Identity and Stereotypes}

Japan is located in the far east of the world, and due to its geographic position, it has no close neighbors. Through most of the Edo period from 1603 to 1868, the country closed its borders to the outside world (Toyosaki \& Eguchi, 2017) and kept its international relations to a minimum. The effects of this inward and controlled homogenization are still evident on the socio-cultural level (Toyosaki \& Eguchi, 2017).

Despite the outward policies of the Meiji restoration and the post-war era rebuilding efforts with Western-influenced industrialization, the concept of westernization of Japan remained an ideological model merely affecting the daily lives of the Japanese. A deep-rooted Japanese self-perception of cultural identity and homogeneity has mostly remained intact (Graburn et al., 2008). According to Parsons (2008), this collective cultural identity results in the cultural hegemony of the majority and the perception of othering.

When group boundaries are defined by stereotypical categorizations, the notion of othering is gradually embedded into the collective identity (Houghton, 2014). This point was emphasized by Kubota and Fujimoto (2013) when they explained the impact of Japanese collective identity on Japanese Americans' daily life experiences in Japan. In their research, Kubota and Fujimoto (2013) argued that differentiation of ethnic minorities based on their observable physical features resulted in the majority distancing themselves from the minority, creating the perception of viewing them as "peripheral, marginal, and incidental" (p. 201).

However, the concept of "othering" does not always appear to be a negative phenomenon. In particular, the Westernization period in Japan played an essential role in creating a positive perception of Caucasian people as the "idealized other" (Kubota \& Fujimoto, 2013). Japanese media portrayals of whiteness as the standard of beauty also helped reinforce the supreme image of white people (Torigoe, 2012; Fujimoto, 2002). The "idealized other" portrayal of Caucasians is also representative of the white English teacher stereotypes conveyed via advertisements for English lessons highlighted in the recent literature (Bailey, 2007; Hooper \& Snyder, 2017; Kubota, 2011; Kubota \& Fujimoto, 2013; Nagatomo, 2016). However, Japanese universities usually try to break from this precedent by embracing globalization and reflecting that in their recruitment practices (Appleby, 2014). In recent years, many universities have ramped up their efforts by hiring from different ethnic and cultural backgrounds. Therefore, intercultural awareness has become a crucial skill for university students in increasingly diverse and complex learning environments.

\section{Intercultural Awareness Building as a Pedagogical Strategy}

Due to rapid globalization, Japanese universities have become increasingly diverse institutions with international faculty members from wide-ranging ethnic and cultural backgrounds. Thus, raising students' intercultural awareness has become critical for the success of potential cross-cultural interactions. In this regard, language teachers need to ensure culture is not transmitted as a "static and fragmented phenomenon" in the classroom. Instead, it should be used as a tool to disrupt the "decontextualized, stereotypical, and misleading" perception of minorities (Houghton, 2014, p. 127). By adopting this reflective and relativistic view, teachers can promote intercultural awareness as a key component of language education (Appleby, 2014; Byram, 1997; Houghton et al., 2018).

Moncada Linares (2016) suggested several reflective classroom teaching methods to raise learners' intercultural awareness in language classrooms. These methods include having pupils reflect on literary and non-literary cultural products to foster intercultural self-reflection and self-consciousness, perform critical discourse analysis, and incite discussions on topics such as identity, difference, and stereotypes. In addition, through qualitative 
research methods, students can collaboratively explore, identify, and suggest possible solutions to cultural practices and behaviors reinforcing the notion of othering. As a result, learners can raise their awareness of unequal power relations between the majority and the minority, and then examine their own biases and prejudices, and develop a more accepting and tolerant attitude (Houghton et al., 2018).

\section{Methodology}

\subsection{Quantitative Method}

This study employs a two-phase exploratory sequential mixed methods design (Creswell, 2013). Firstly, a quantitative instrument was designed based on the research questions of "What are Japanese university students' perceptions of FETs?" and "What are the potential implications of students' perceptions of FETs?" These research questions were constructed through the themes derived from the existing literature. These themes include ethnic stereotypes, comparison of FETs and JTEs, and learner anxiety towards FETs. A large sample size ( $\mathrm{n}=377)$ was used to make more accurate interpretations of students' perceptions and the challenges facing FETs. The survey was conducted with first and second-year EFL students from four Japanese universities in the greater Tokyo area. The questionnaire consisted of five affirmative perception statements (APSs) based on a five-point Likert scale ranging from $1=$ strongly disagree to $5=$ strongly agree (See table 1 below).

The items in the questionnaire were designed to identify the potential predictive power of the five APSs through the mean and standard deviation values (see table 4). Before delivering the survey questionnaire, students were given a consent form to fulfill the ethical standards. All questions were translated into Japanese, and the Japanese translations were included in the survey. In addition, students were provided with opportunities to ask for clarification. Since anonymity was employed in this study, students' personal identification was not revealed.

Table 1. Affirmative perception statements

\begin{tabular}{|c|c|c|c|c|c|c|c|c|c|}
\hline \multirow{3}{*}{$\begin{array}{l}\text { Values: } \\
\mathrm{S} / \mathrm{N} \\
\text { (i) }\end{array}$} & \multirow{2}{*}{\multicolumn{2}{|c|}{$\begin{array}{c}\text { 1-Strongly disagreed } \quad \text { 2-Disagree } \\
\text { Affirmative Perception Statements }\end{array}$}} & \multirow[t]{2}{*}{ 3-Neutral } & \multirow[t]{2}{*}{ 4-Agree } & \multicolumn{5}{|c|}{ 5- Strongly agree } \\
\hline & & & & & \multicolumn{5}{|c|}{ Values } \\
\hline & I feel anxious when I spe & vith my FET. & & & 1 & 2 & 3 & 4 & 5 \\
\hline (ii) & I feel more comfortable & ing English w & ny FET. & & 1 & 2 & 3 & 4 & 5 \\
\hline (iii) & I view my FET as more & entertainer. & & & 1 & 2 & 3 & 4 & 5 \\
\hline (iv) & My FET should be of Ar & an/European & age & & 1 & 2 & 3 & 4 & 5 \\
\hline (v) & $\begin{array}{l}\text { My FET of Asian descen } \\
\text { a teacher of American/E }\end{array}$ & $\begin{array}{l}\text { teach me the } \\
\text { an heritage. }\end{array}$ & age and cu & s effectively as & 1 & 2 & 3 & 4 & 5 \\
\hline
\end{tabular}

\subsection{Qualitative Method}

The qualitative instrument was designed to explain and build upon the quantitative results (Creswell, 2013). Therefore, two focus groups were formed with eight students who had also participated in the survey. Both male and female students were selected based on their prior language learning experiences with male FETs from predominantly Western backgrounds. The instrument was initially sampled with bilingual Japanese English teachers. The interview protocol followed research ethics principles assuring anonymity and confidentiality for all participants. Before the interviews, each student was asked to sign an informed consent form and assured that they had the right to use a pseudonym and withdraw from the research at any time.

The interviews were held with four students at a time. This procedure allowed a smaller group of students to feel comfortable elaborating on their experiences and personal stories. Various visual aids and props were also used to ensure students understood the questions accurately. At first, the participants were provided with the background and the objectives of the study. Since the primary researcher who conducted the interviews was a fluent Japanese language speaker, the participants were allowed to answer questions in Japanese. A bilingual Japanese teacher was also present to make sure all items were understood. The interviews were recorded, and the researcher identified the repeated patterns and clustered them as emergent themes for analysis. 
Table 2. Participant information

\begin{tabular}{lccl}
\hline NAME & AGE & GENDER & SCHOOL YEAR \\
\hline SAORI & 19 & FEMALE & First-year \\
SEIYA & 20 & MALE & Second-year \\
KEN & 19 & MALE & First-year \\
YUMI & 19 & FEMALE & First-year \\
MIZUKI & 19 & FEMALE & First-year \\
SENA & 20 & FEMALE & Second-year \\
MIKIYA & 20 & MALE & Second-year \\
TAKA & 20 & MALE & Second-year \\
\hline
\end{tabular}

\section{Findings}

\subsection{Quantitative Data Analysis}

The quantitative data was analyzed through the mean and standard deviation values for each APS. Based on the Likert scale, 1 (strongly disagree) and 5 (strongly agree) indicated a central tendency and a low dispersion, while all the other variables in-between point to an absence of precision and a high measure of dispersion. As the APSs I and II indicated, the majority of the participants did not feel anxious about speaking with their FETs yet still opted to study English with JTEs (see table 3). In addition, most participants viewed their FETs as scholarly individuals and did not agree on personality and ethnic stereotyping. However, the results from the APS III suggested that a significant number of participants still viewed their FETs as more of an entertainer and less of a scholar.

The responses for the APS IV indicated that a significant number of the participants preferred to be taught English by FETs of European/American heritage, yet many of them also remained neutral (see table 3). This could mean they either had no preference for the specific APS or avoided expressing their position. The same trend can also be observed in the values for the APS V. The split division of opinions indicated that FETs' ethnic background was regarded as a factor in teaching language and culture (see table 3, the APS V).

Table 4 demonstrates the mean and standard deviation values for each APS. The standard deviation values suggested a high dispersion measure with no value recorded above 1.5. The mean values also varied between 3.36 and 2.35, showing an absence of precision. Despite the absence of a central tendency and a high dispersion measure, certain outliers were observed in the values. A large number of participants viewed their FETs as more of an entertainer, preferred FETs of American/European heritage, and believed FETs of Asian descent may not be able to teach the language and culture as effectively as FETs of American/European heritage. These results warranted further investigation. Thus, qualitative research was performed to help explain and build upon the quantitative results.

Table 3. Quantitative survey results

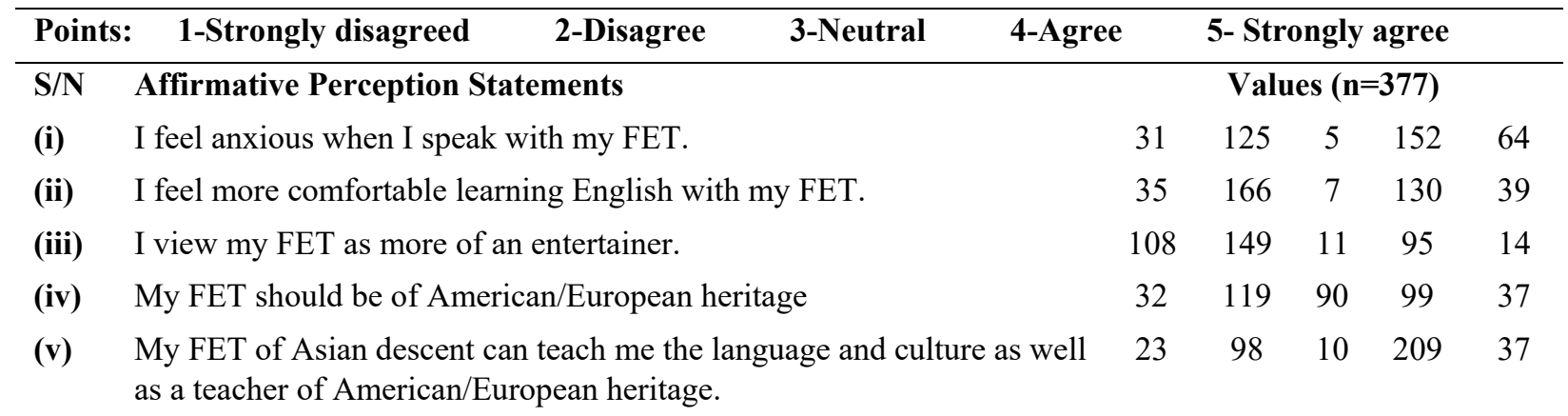


Table 4. Mean and standard deviation values

\begin{tabular}{|c|c|c|c|c|c|}
\hline Points: & 1-Strongly disagreed & 2-Disagree & 3-Neutral & 4-Agree & 5- Strongly agree \\
\hline $\mathbf{S} / \mathbf{N}$ & \multicolumn{4}{|c|}{ Affirmative Perception Statements } & Standard Deviation \\
\hline (i) & \multicolumn{4}{|c|}{ I feel anxious when I speak with my FET. } & 1.29 \\
\hline (ii) & \multicolumn{4}{|c|}{ I feel more comfortable learning English with my FET. } & 1.25 \\
\hline (iii) & \multicolumn{4}{|c|}{ I view my FET as more of an entertainer. } & 1.23 \\
\hline (iv) & \multicolumn{4}{|c|}{ My FET should be of American/European heritage } & 1.14 \\
\hline (v) & \multicolumn{4}{|c|}{$\begin{array}{l}\text { My FET of Asian descent can teach me the language and culture as well } \\
\text { as a teacher of American/European heritage. }\end{array}$} & 1.14 \\
\hline
\end{tabular}

6.2 Qualitative Data Analysis

The qualitative data analysis revealed a number of emergent themes through the participants' responses to the interview questions informed by the quantitative findings (see appendix 1). The interview questions sought to understand the participants' perceptions of phenotypical, gender, and personality stereotypes of FETs, FETs from non-American/non-European heritage, the role of mass media in their perceptions, and the potential implications of intercultural awareness-building activities through their personal experiences in EFL classes. The emergent themes from the two focus group interviews are listed as follows:

- Phenotypical FET stereotypes in Japan

- Gender stereotypes of FETs in Japanese EFL classes

- Common FET personality stereotypes

- FETs from non-American/non-European heritage

- The role of the mass media

- Intercultural activities in EFL classes

6.2.1 Phenotypical FET Stereotypes in Japan

At first, the researcher started the focus group interviews by showing the participants images of FETs of Asian, African, and Caucasian descent. The visual aids were designed to help students grasp the meaning of the questions regarding phenotypical and gender stereotypes. All participants selected the picture of a male Caucasian teacher as the most prevalent FET stereotype in Japan. The participants highlighted their lack of experience in studying with FETs of non-American/non-European heritage. In this regard, several participants emphasized the common assumption of viewing Americans as mainly Caucasians regardless of the country's ethnic and cultural diversity.

Yumi, a first-year student, noted, "The white man in the image is the kind of face that reminds me of an English teacher from the U.S." Consistent with Yumi's comment, Mizuki, a first-year student, also said, "A person who can speak English must be from America, and when we think about native Americans, we assume that they are all white people, not necessarily Africans or Asians."

Several other students emphasized Japanese people's desire to learn "natural English expressions" with "accurate pronunciation" from "teachers of American/European heritage." In this regard, Saori, a first-year student, noted, "FETs of American/European descent can teach us natural English words and more accurate pronunciation than Asian FETs," while Mikiya and Ken, who are both second-year students, said, "Asian teachers sometimes cannot pronounce words correctly." In addition, Taka, who is also a sophomore, talked about his exposure to Caucasian FETs through EFL textbooks. Taka said, "I only remember the images of Caucasian people in my high school English language textbooks, so when I entered university, I assumed that my English teacher would be Caucasian."

\subsubsection{Gender Stereotypes of FETS in Japanese EFL Classes}

The participants were also shown images of male and female FETs to reflect on their perception of gender stereotypes. The majority of them suggested that male FETs are more prevalent than females, while two of the participants preferred not to comment. Several participants emphasized their lack of experience studying with female FETs during their pre-tertiary and college English education. Sena and Yumi attributed this to the gender gap in workplaces in Japan. Yumi also noted, "In Japan, the majority of full-time workers are male, so it's not unusual to see male teachers." Saori associated male teachers with authority and said, "Students are more intimidated by male teachers than their female colleagues." Saori also noted Japanese schools emphasize "discipline," and thus, male teachers are given preference. 


\subsubsection{Common FET Personality Stereotypes}

Following the phenotypical and gender stereotypes, the participants were asked to reflect on common personality stereotypes of FETs. The participants agreed upon the expectation that FETs should be "fun and entertaining." Seiya elaborated on his experiences with his high school English teacher, "We often played games in our FET's classes and didn't treat it as seriously as the classes taught by our Japanese English teacher." Ken further emphasized this point by saying that his Japanese English teacher only taught grammar due to his lack of oral English competence. Ken noted, "My English teacher did not want to speak English in front of us because he was afraid to make mistakes."

Sena also elaborated on her own experience in college. Her FET was teaching them "conversation through games and fun activities," while the focal point of her classes with JTEs was "translation." In addition, other students drew comparisons between FETs and JTEs using certain adjectives such as FETs being "outgoing," "entertaining," "animated," "having a big voice." Students also ascribed certain adjectives to their JTEs, such as "serious," "calm," "boring." Mizuki said:

During the fall semester, my JTE had a really small voice. Even though we sometimes had speaking activities, such as practicing dialogues from a textbook, I sometimes fell asleep during the dialogue and forgot my JTE was in the classroom.

\subsubsection{FETs of Non-American/Non-European Heritage}

The question about FETs' heritage emerged from the quantitative findings. As stated in the quantitative analysis, a significant number of participants preferred to study English with FETs of American/European heritage. When the focus groups were asked to share their experiences, the participants reiterated their position on the benefits of studying with FETs of European/American heritages, such as their English being easier to understand and Caucasian FETs being more "fun to study with." Seiya emphasized this point by using words such as "clear pronunciation" and "fun to study with" when describing his experiences with FETs of European/American heritage. Ken also noted, "White people pronounce English words more clearly." Both Saori and Taka associated "English culture" with "Western people." According to Saori, "The main advantage of studying with a Western teacher is to learn about the culture of Western people."

On the other hand, Mikiya and Yumi reflected on their ethnic background and noted, "It is more appealing to study English with a teacher from outside of Asia." However, Seiya and Ken both had the experience of studying English with "Filipino teachers." Therefore, they considered them in the same group as their Caucasian peers. Ken noted, "I often take private English conversation lessons with Filipino teachers on campus. They are fun and energetic. They also speak with clear pronunciation."

\subsubsection{The Role of the Mass Media}

The role of the mass media in stereotyping was highlighted in the previous literature. Therefore, the researchers determined that it would be beneficial to ask the participants how they viewed the mass media's influence on their perceptions of FETs. The participants agreed on the media's extensive coverage of Caucasians among the minorities in Japan. Seiya mentioned two TV personalities, "Pakkun" and "Atsugiri Jayson" as Caucasian celebrities regularly featured on Japanese TV. Saori and Sena both mentioned "the negative portrayal of Africans" on the news. Mizuki further elaborated on this point by emphasizing the media's association of Africans with words such as "hunger, poverty, and disease."

The participants also noted positive media portrayal of Caucasians and non-recognition, or negative coverage strategies against people from Africa or other Asian countries were influential in building a negative perception of people from non-American/non-European heritage. Ken said, "It is easy to develop an overly positive image of Caucasian people and negative image of Africans and people from other Asian countries because of the mass media."

\subsubsection{Intercultural Activities in EFL Classes}

The final theme emerged from the participants' personal experiences with intercultural awareness-raising activities in their EFL classes. The participants confirmed that they had taken part in intercultural awareness-raising activities in their EFL classes. Ken was given the opportunity to "research, write, and present about African Americans in the U.S." He believed that being directly engaged in the intercultural awareness-raising activity helped him gain insight into the minority issues in different countries and made him more "empathetic" towards them. Ken also emphasized the benefit of this project for his "language development." Similarly, Seiya elaborated on his experiences with intercultural awareness-raising activities: 
After thoroughly researching the struggles of the international community in Japan, I realized the international community extends beyond Americans, the Chinese, and Koreans in Japan. People from other ethnic and cultural backgrounds also live here.

Sena emphasized the influence of intercultural storytelling activities on her perception of Caucasians. The story was about a Caucasian man and his struggle with Japanese shop clerks due to his lack of English language competence. Thanks to this story, Sena revisited her own beliefs about Caucasian stereotypes and realized that "Not all Caucasians are native English speakers."

Several participants also indicated that intercultural activities in EFL classes could become more effective when students relate to their lived experiences. For her final English presentation, Yumi decided to research and present gender stereotypes in Japan. Yumi was raised in an environment where there were strictly defined gender roles, such as "females should stay home and do house chores" and "Males should go to work and bring money." Yumi noted:

Because I was actively involved in researching and presenting gender stereotypes in Japan, it helped me recognize my own biases about different gender roles in society. I now believe different roles should no longer exist. Men should do more things in home while women should be more active at work.

Mikiya, who described himself as $h a-f u$ (a Japanese term for mixed-race children), also believes watching presentations on "intercultural issues," such as "gay marriage in Japan," "ha-fu," "minorities," and "gender stereotypes" allowed him to self-reflect and recognize his own biases and prejudices. Mikiya noted, "I realize that I should be more tolerant and accepting towards minorities if I am to expect others to treat me the same way."

\section{Discussion}

When the researchers were gathering sources for this study, it was evident that there was a lack of large-scale quantitative research seeking to understand students' perceptions. Therefore, using a quantitative method provided a strong premise for this research by offering insights into students' perceptions of their FETs and teacher-student dynamics in intercultural contexts. By utilizing the outliers from the quantitative data, the researchers had the opportunity to design a complementary qualitative instrument and build upon that premise.

As the quantitative analysis revealed, the participants associated certain linguistic and cultural attributes with FETs' ethnic backgrounds. Many of them, if not the majority, preferred to study with FETs of European/American descent. However, the qualitative analysis indicated that firsthand experience of studying with FETs of non-American/non-European descent could help offset students' biases towards those teachers. Another finding from the quantitative data was the majority of the participants did not opt to study English with FETs of European/American heritage. This could be indicative of firsthand experience with FETs of non-American/non-European descent. In this regard, future research may offer new insights into students' experiences with FETs of non-American/non-European descent.

As the qualitative analysis indicated, the participants' perception of gender stereotypes sheds light on the current gender gap in Japanese educational settings. Therefore, a collaborative effort by university personnel, school administrators, and students may help influence universities' recruitment strategies to promote gender equity in educational settings. In addition, research seems to be lacking on the media's influence on English education in Japan despite the presence of wide-ranging TV coverage and print advertisements promoting English conversation schools. Thus, it would be safe to say that research seems to be lagging behind the reality at present. In this regard, the qualitative findings from this study could provide the groundwork for future research to gain a better understanding of the media's influence on creating and reinforcing FET stereotypes in Japanese EFL settings.

During the focus group interviews, the primary researcher's ability to speak Japanese combined with the support of a Japanese teacher in the room provided psychological safety for the participants to express their views on FET stereotypes. However, the participants generally avoided expressing negative comments about Caucasian FETs. This point can be seen as a limitation due to the presence of the primary researcher whom the students may have perceived as a Caucasian teacher. Thus, while the focus group interviews may provide a useful model for future qualitative studies involving Japanese students, it may also be beneficial to experiment with qualitative models, excluding the researcher from the data gathering process.

The qualitative element of this study also emphasized the benefits of intercultural activities to build students' intercultural awareness with a broader perspective of language teaching and learning. Each participant shared their own personal experiences of intercultural awareness-raising research and presentation activities, discussion sessions, and intercultural stories. The responses indicated that these activities helped students develop their self-awareness. During each activity, students were able to reflect on themselves, recognize their biases and learn 
to think beyond these preconceived notions. Especially when students related to an intercultural activity, they felt more motivated to engage in the activity. Enhanced motivation and engagement were also reflected positively in students' language skills.

In this regard, EFL classes can be viewed as an effective platform for students to develop both their intercultural and language competence. Particularly, classes taught by FETs present a rare opportunity where students can engage in firsthand intercultural interactions with people from different ethnic and cultural backgrounds. As a result, students can have the opportunity to re-evaluate their beliefs and assumptions about FETs. Therefore, it is both the teacher's and students' interest to give themselves a window into a wider world through intercultural activities.

\section{Conclusion}

This study attempted to explore Japanese university students' perceptions of foreign English teachers (FETs) through a two-phased exploratory sequential mixed-methods design. The study sought to answer the research questions of "What are the potential implications of students' perceptions?" and "What challenges emerge from those perceptions?" The quantitative data revealed a number of fundamental issues concerning FET stereotypes within the Japanese university EFL context. In this regard, the qualitative data provided a more nuanced understanding of phenotypical, gender, and personality stereotypes associated with FETs and their potential implications for teachers who fell outside of these stereotypical categorizations.

The qualitative findings confirmed the existence of phenotypical, gender, and personality FET stereotypes in Japanese university EFL classes. Students' prior educational experiences, socio-cultural factors, and the mass media were found to be influential in constructing and reinforcing the aforementioned stereotypes. The participants also believed intercultural activities were beneficial for them to develop a more tolerant and accepting attitude. In particular, when students related to intercultural activities, they could enhance their linguistic and intercultural awareness. In this regard, a future qualitative study on FETs' perceptions of FET stereotypes and the benefits of intercultural activities in EFL classes could have the potential to offer valuable insights into teachers' perception of this phenomenon and help raise awareness among EFL professionals and school administrators in Japanese universities.

\section{References}

Appleby, R. (2014). Man and masculinities in global language teaching. Springer. https://doi.org/10.1057/9781137331809

Bailey, K. (2007). Akogare, ideology, and 'Charisma Man', mythology: Reflections on ethnographic research in English language schools in Japan. Gender, Place \& Culture, 14(5), 585-608. https://doi.org/10.1080/09663690701562438

Benson, P. (2013). Teaching and researching: Autonomy in language learning. Routledge. https://doi.org/10.4324/9781315833767

Brewer, G. (2011). Media psychology. Macmillan International Higher Education. https://doi.org/10.1007/978-0-230-35720-4

Creswell, J. W. (2013). Educational research: Pearson new international edition: Planning, conducting, and evaluating quantitative and qualitative research. Pearson Higher Ed.

Dornyei, Z. (2013). The psychology of second language acquisition. OUP. https://doi.org/10.4324/9781410613349

Esaki, Y., \& Shintani, R. (2010). English education in Japan's elementary schools: Reforms and challenges. Asia Pacific World, 1(1), 133-153. https://doi.org/10.3167/apw.2010010109

Fukuda, C. (2017). Gaijin performing gaijin ('A foreigner performing a foreigner'): Co-construction of foreigner stereotypes in a Japanese talk show as a multimodal phenomenon. Journal of Pragmatics, 109, 12-28. https://doi.org/10.1016/j.pragma.2016.12.012

Graburn, N. H., Ertl, J., \& Tierney, R. K. (2008). Multiculturalism in the new Japan: Crossing the boundaries within. Berghahn Books.

Hooper, D., \& Snyder, W. (2017). Becoming a "real" teacher: A case study of professional development in eikaiwa. The European Journal of Applied Linguistics and TEFL, 6(2), 183-201.

Hosoki, Y. (2011). English language education in Japan: Transitions and challenges. Kyushu International University International Relations Studies, 6(1). Retrieved from https://id.nii.ac.jp/1265/00000272/ 
Houghton, S. A. (2014). Researching the stereotypes of people around me: An introductory thesis writing course for international students. Cambridge Scholars Publishing.

Houghton, S. A., Furumura, Y., \& Lebedko, M. (2014). Critical cultural awareness: Managing stereotypes through intercultural (Language) education. Cambridge Scholars Publishing.

Houghton, S. A., Rivers, D. J., \& Hashimoto, K. (2018). Beyond Native Speakerism: Current explorations and future visions. Routledge. https://doi.org/10.4324/9781315643601

Kawashima, T. (2009). FL anxiety studies of Japanese EFL learners: A critical review. In A. M. Stoke (Ed.), JALT 2008 Conference Proceedings. JALT.

King, J. (2013). Silence in the second language classroom. Springer. https://doi.org/10.1057/9781137301482

Kubota, R. (2011). Learning a foreign language as leisure and consumption: Enjoyment, desire, and the business ofeikaiwa. International Journal of Bilingual Education and Bilingualism, 14(4), 473-488. https://doi.org/10.1080/13670050.2011.573069

Kubota, R., \& Fujimoto, D. (2013). Racialized native speakers: Voices of Japanese American English language professionals. In Houghton A. S., \& Rivers, J. D. (Eds.), Native speakerism in Japan: Intergroup dynamics in foreign language education. Multilingual Matters. https://doi.org/10.21832/9781847698704-018

Loucky, J. P., \& Ware, J. L. (2016). Flipped instruction methods and digital technologies in the language learning classroom. IGI Global. https://doi.org/10.4018/978-1-5225-0824-3.ch001

Merskin, L. D. (2011). Media, minorities and meaning: A critical introduction. Peter Lang.

MEXT (Ministry of Education, Culture, Sports, Science and Technology in Japan). (2014a). English Education. Retrieved from https://www.mext.go.jp/english/topics/

Moncada Linares, S. (2016). Othering: Towards a critical cultural awareness in the language classroom. $H O W$, 23(1), 129-146. https://doi.org/10.19183/how.23.1.157

Nagatomo, D. H. (2015). In the ivory tower and out of the loop: Racialized and gendered identities of university EFL teachers in Japan. In Y. L. Cheung, S. B., \& Said, K. Park (Eds.), Advances and current trends in language teacher identity research (pp. 124-137). Routledge. https://doi.org/10.4324/9781315775135

Nagatomo, D. H. (2016). Identity, gender and teaching English in Japan. Multilingual Matters. https://doi.org/10.21832/9781783095216

Nakane, I. (2007). Silence in intercultural communication. John Benjamins Publishing. https://doi.org/10.1075/pbns.166

Saiki, T., Mukohara, K., Otani, T., \& Ban, N. (2011). Can Japanese students embrace learner-centered methods for teaching medical interviewing skills? Focus groups. Medical Teacher, 33(2), 69-74. https://doi.org/10.3109/0142159X.2011.536061

Sani, S. (2013). Hatred for black people. Xlibris Corporation.

Shimizu, (2000). Japanese college student attitudes towards English teachers: A survey. The Language Teacher, $19(10), 5-8$.

Toyosaki, S., \& Eguchi, S. (2017). Intercultural communication in Japan: Theorizing, homogenizing discourse. Routledge. https://doi.org/10.4324/9781315516936

Walkinshaw, I., \& Oanh, H. D. (2014). Native and non-native English language teachers: student perceptions in Vietnam and Japan. Sage Open, 1(9). https://doi.org/10.1177/2158244014534451

Yazawa, O. (2017). Students' perception of native English-speaking teachers and Japanese teachers of English: The effect on students' self-efficacy and emotional state. Eruditi, 1(3), 61-72.

Yoshimoto, M., Tsai, E., \& Choi, J. (2010). Television, Japan and globalization. University of Michigan Press. https://doi.org/10.3998/mpub.9340049

\section{Copyrights}

Copyright for this article is retained by the author(s), with first publication rights granted to the journal.

This is an open-access article distributed under the terms and conditions of the Creative Commons Attribution license (http://creativecommons.org/licenses/by/4.0/). 